\title{
Congestive Myelopathy Due to Cervical Perimedullary Arteriovenous Fistula Evaluated by Apparent Diffusion Coefficient Values
}

\author{
-Case Report-
}

\author{
Tomoo INOUE, Toshiyuki TAKAHASHI, Hiroaki SHIMIZU, \\ Yasushi MATSUMOTO*, Akira TAKAHASHI**, \\ and Teiji TOMINAGA***
}

\begin{abstract}
Departments of Neurosurgery and *Neuroendovascular Therapy, Kohnan Hospital, Sendai, Miyagi; Departments of ${ }^{* *}$ Neuroendovascular Therapy and ${ }^{* * *}$ Neurosurgery,

Tohoku University Graduate School of Medicine, Sendai, Miyagi
\end{abstract}

\begin{abstract}
A 22-year-old woman presented with a cervical perimedullary arteriovenous fistula (AVF) manifesting as right upper and lower extremity weakness. $T_{2}$-weighted magnetic resonance (MR) imaging showed intramedullary hyperintensity believed to be caused by venous congestion. Preoperative diffusionweighted MR imaging showed increased apparent diffusion coefficient (ADC) value. Spinal angiography demonstrated an AVF fed mainly by the right C-5 radicular artery. Complete obliteration of AVF was achieved by endovascular embolization and microsurgical shunt occlusion. The ADC value was normalized and her neurological deficits improved after endovascular surgery, whereas $T_{2}$-weighted MR imaging still demonstrated the lesion. The high preoperative ADC value probably indicated reversible vasogenic edema and immediate normalization of the ADC value suggests a good clinical outcome.
\end{abstract}

Key words: cervical spine, perimedullary arteriovenous fistula, apparent diffusion coefficient, venous congestion, myelopathy

\section{Introduction}

Spinal arteriovenous malformation (AVM) covers a heterogeneous group of vascular anomalies, classified as dural arteriovenous fistula (AVF), perimedullary AVF or AVM, and intramedullary AVF or AVM. ${ }^{6,11,17)}$ In particular, perimedullary spinal AVF is a distinctive spinal vascular anomaly with characteristic clinical features. ${ }^{8-10)}$ Such vascular anomalies have high potential for causing neurological deterioration including hemorrhage, venous hypertension, vascular steal, and mass effect caused by varix or aneurysm..$^{8)}$ Subarachnoid hemorrhage is a well known clinical presentation.5) Neurological deficits may be aggravated by congestive myelopathy, which is possibly reversible with the correct diagnosis and treatment. ${ }^{9,13)}$ Prolonged impairment of spinal cord perfusion could lead to irreversi- ble subacute necrotizing myelopathy, also known as Foix-Alajouanine syndrome. ${ }^{3)}$ Congestive myelopathy may occur with vasogenic edema, which is potentially reversible, or cytotoxic edema, which is irreversible. ${ }^{9)}$

Rapid diagnosis of reversible congestive myelopathy is essential as prolonged venous varicosity may lead to irreversible myelopathy. ${ }^{3)}$ Conventional magnetic resonance (MR) imaging is useful to identify spinal AVM, ${ }^{4)}$ but cannot evaluate the reversibility of venous congestive myelopathy. Diffusionweighted MR imaging can supply pathophysiological information because of the characteristic changes in the apparent diffusion coefficient (ADC) values. ${ }^{10)}$ ADC is widely used to evaluate intracranial diseases, ${ }^{15)}$ but not spinal cord diseases because of the presence of severe image artifacts induced by physiological motion and magnetic susceptibility

Received April 10, 2006; Accepted July 8, 2006

Author's present address: T. Inoue, M.D., Department of Neurosurgery, Ohara Medical Center, Fukushima, Japan. 
variations around the spine..$^{2,7,14)}$

We evaluated a case of cervical perimedullary AVF with congestive myelopathy using line-scan diffusion-weighted MR imaging to correlate the ADC values and the clinical characteristics.

\section{Materials and Methods}

A 1.5-tesla MR imaging system (GE Signa Horizone; General Electric, Milwaukee, Wis., U.S.A.) equipped with echo-planar imaging (EPI) capabilities was used for all procedures. A phased array spine coil was used to minimize motion artifacts. After acquiring survey images, fast spin $\mathrm{T}_{2}$-weighted gradient echo EPI sequences were obtained in sagittal sections (repetition time [TR] $4000 \mathrm{msec}$, echo time [TE] $98.9 \mathrm{msec}$, slice thickness $5 \mathrm{~mm}$, field of view $240 \times$ $180,128 \times 128$ pixels). Line-scan diffusion-weighted MR imaging was then performed (TR $3135 \mathrm{msec}$, TE $68.3 \mathrm{msec}$, slice thickness $5 \mathrm{~mm}$, field of view $240 \times$ $180,128 \times 128$ pixels) with b value of $1000 \mathrm{sec} / \mathrm{mm}^{2}$. Trace ADC maps were plotted according to Stejskal and Tanner. ${ }^{10)}$ Regions of interest were positioned at the C-3 level where $\mathrm{T}_{2}$-weighted $\mathrm{MR}$ imaging showed intramedullary areas of high intensity. The abnormal areas were outlined on the ADC maps using the conventional images as guides, and the pre- and post-treatment ADC values were calculated and compared to those measured in six normal volunteers $\left(0.954 \times 10^{-3} \mathrm{~mm}^{2} / \mathrm{sec}\right)$.

\section{Case Report}

A 22-year-old right-handed woman visited to another hospital after sudden onset of right upper limb weakness. The patient had suffered from cervical pain and right upper extremity numbness for 1 week before consultation. The initial diagnosis was cervical spondylosis, and she was treated with nonsteroidal anti-inflammatory drugs. However, she consulted our hospital because of neurological deterioration.

On admission, neurological examination disclosed hypesthesia and weakness below the C-5 level in the right hand, and vibration disturbance in the right hand and leg. $\mathrm{T}_{2}$-weighted $\mathrm{MR}$ imaging demonstrated flow voids from the C-1 to C-4 levels and intramedullary hyperintensity below C-2 (Fig. 1A). Diffusion-weighted MR imaging of the cervical cord at the C-1 to C-5 levels showed intramedullary areas of slight hyperintensity. The ADC value at C-3 was higher $\left(1.09 \times 10^{-3} \mathrm{~mm}^{2} / \mathrm{sec}\right)$ than the mean value in the normal volunteers $\left(0.954 \times 10^{-3} \mathrm{~mm}^{2} / \mathrm{sec}\right)$ (Fig. 1B). Spinal angiography demonstrated a cervical perimedullary AVF fed mainly by the right
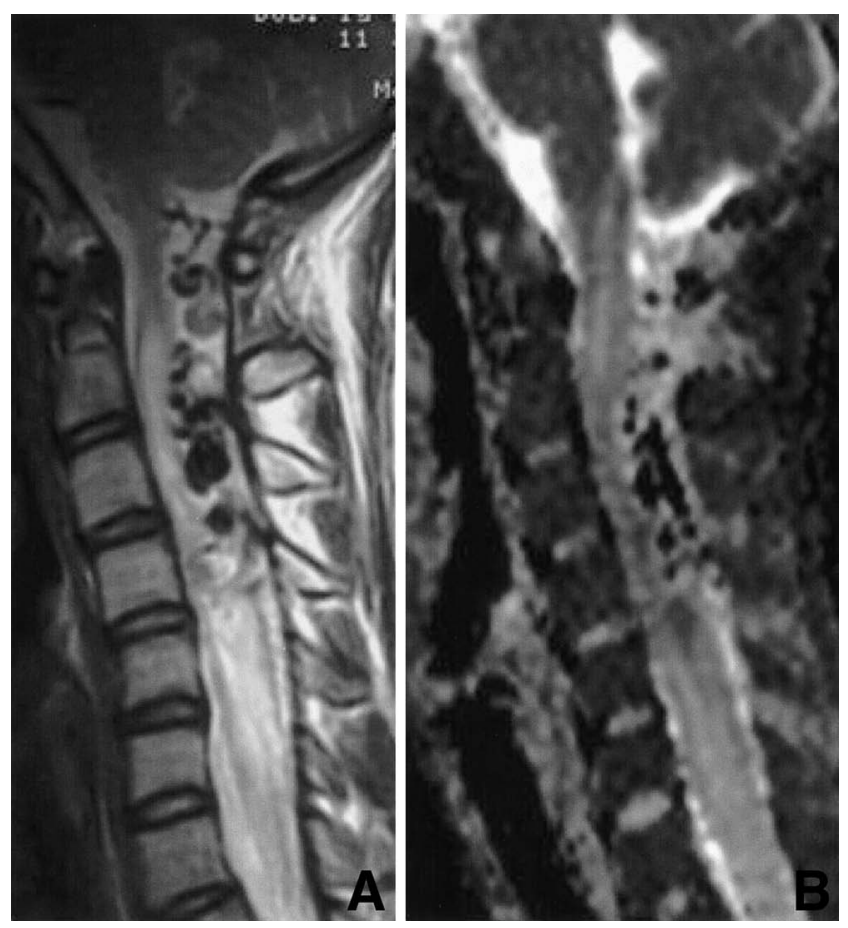

Fig. 1 A: Preoperative $T_{2}$-weighted magnetic resonance image demonstrating flow voids from the C-1 to C-4 levels and intramedullary hyperintensity below C-2, indicating venous congestion. B: Preoperative apparent diffusion coefficient (ADC) map showing a lesion in the cervical cord, with higher ADC value compared to normal volunteers.

C-5 radicular artery and drained by the bilateral superior petrosal sinuses and radicular veins. A feeding artery to the anterior spinal artery was also observed (Fig. 2A).

Endovascular embolization by N-butyl-cyanoacrylate was initially performed to induce collapse of the massive dilated ascending draining vein and reduce the blood flow. The ADC value $\left(0.955 \times 10^{-3} \mathrm{~mm}^{2} /\right.$ sec) decreased almost to the mean value of the normal volunteers $\left(0.954 \times 10^{-3} \mathrm{~mm}^{2} / \mathrm{sec}\right) 1$ week after endovascular surgery (Fig. 3B). However, conventional MR imaging showed that the lesion had not fully resolved (Fig. 3A). Direct surgery was planned 2 weeks after the endovascular treatment because the descending draining vein was revealed and right hand weakness still persisted.

Right hemilaminectomy, right C-3 and C-5 partial laminectomy, and dural opening exposed the partially thrombosed posterior spinal vein. Two feeding arteries were found around the C-5 root, one artery had been obliterated by embolization, and the other was shunted to the draining vein. After coagulation 

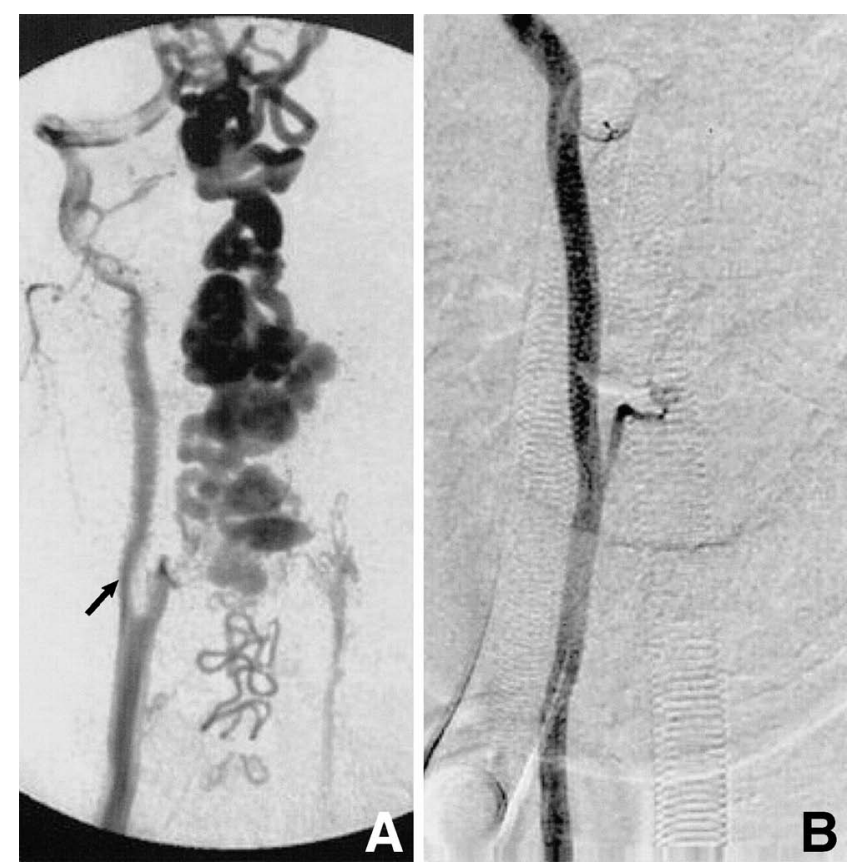

Fig. 2 A: Preoperative spinal angiogram demonstrating a perimedullary arteriovenous fistula fed by the right $\mathrm{C}-5$ radicular artery (arrow) and drained by the bilateral superior petrosal sinuses and radicular veins. B: Intraoperative angiogram revealing disappearance of the draining vein.

of the feeding artery just distal to the shunt, intraoperative spinal angiography confirmed disappearance of the draining vein and preservation of the feeding artery to the anterior spinal artery (Fig. 2B).

$\mathrm{T}_{2}$-weighted MR imaging obtained 6 weeks after the surgery demonstrated that the flow voids had disappeared. She noted gradual resolution of the right upper extremity weakness within 4 months of the operation.

\section{Discussion}

Diffusion-weighted MR imaging is a well-established methodology to distinguish the time course of vasogenic and cytotoxic edema in intracranial disease. ${ }^{12,15)}$ Vasogenic edema is characterized by higher ADC values compared with those of normal brain tissue, because of the increased water content in the extracellular space where water is less restricted. ${ }^{15)}$ Diffusion-weighted MR imaging includes both $\mathrm{T}_{2}$-weighted and diffusion-weighted components, so vasogenic edema may appear as hypointense, isointense, or slightly hyperintense on diffusion-weighted images, but always hyperintense
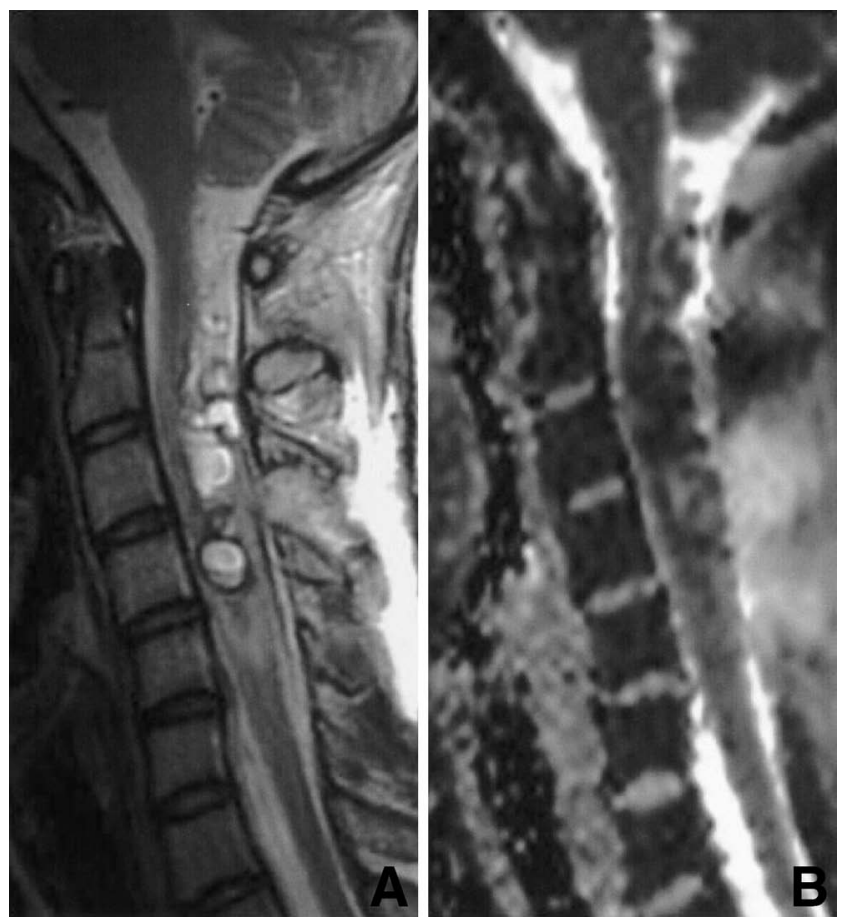

Fig. 3 A: $T_{2}$-weighted magnetic resonance image obtained 1 week after the endovascular surgery still demonstrating the spinal cord edema, and embolic material (N-butylcyanoacrylate) as a hyperintense area. B: Postoperative apparent diffusion coefficient map revealing disappearance of the hyperintense lesion.

on ADC images. On the other hand, cytotoxic edema appears as hyperintense on diffusion-weighted images and hypointense on ADC images.

Diffusion-weighted MR imaging of the spinal cord suffers from magnetic susceptibility artifacts due to the presence of bone and air, and closed vascular and cerebrospinal fluid pulsation. ${ }^{7)}$ In contrast, linescan diffusion-weighted MR imaging is not affected by magnetic susceptibility and bulk motion, so is useful for imaging the spinal cord. ${ }^{1)}$ In our case, preoperative line-scan diffusion-weighted MR imaging could successfully demonstrate the lesion of the spinal cord as hyperintense on the ADC maps, which was thought to reflect reversible vasogenic edema. These findings reflect the neurological exacerbation which was supposed to result from venous congestion due to vasogenic edema.

Measurement of the ADC values in cases of congestive myelopathy may allow prospective evaluation of the reversibility of the clinical features and establish the optimum strategy for the patient. Both $\mathrm{T}_{2}$-weighted $\mathrm{MR}$ imaging findings and ADC values were reported to be normalized in a previous patient 
with dural AVF after 2 months of treatment. ${ }^{16)}$ In our case, the ADC value was normalized only 1 week after endovascular intervention, but $\mathrm{T}_{2}$-weighted MR imaging still showed abnormal intramedullary hyperintensity. The pathological improvement of the spinal cord was dramatic after flow reduction in the AVF. Although neurological recovery could be expected after endovascular embolization, additional microsurgery was performed to achieve complete obstruction of AVF and to avoid aggravation of the residual arteriovenous shunt.

Immediate normalization of the ADC value may indicate improvement of the clinical symptoms, even though $\mathrm{T}_{2}$-weighted $\mathrm{MR}$ imaging continues to show abnormal intramedullary hyperintensity. Further investigation is necessary to determine the relationship of the ADC values and the severity of venous return, and follow-up postoperative changes.

\section{References}

1) Bammer R, Herneth AM, Maier SE, Butts K, Prokesch RW, Do HM, Atlas SW, Moseley ME: Line scan diffusion imaging of the spine. AJNR Am J Neuroradiol 24: 5-12, 2003

2) Clark CA, Werring DJ: Diffusion tensor imaging in spinal cord: methods and applications - a review. NMR Biomed 15: 578-586, 2002

3) Criscuolo GR, Oldfield EH, Doppman JL: Reversible acute and subacute myelopathy in patients with dural arteriovenous fistulas. Foix-Alajouanine syndrome reconsidered. J Neurosurg 70: 354-359, 1989

4) Gilbertson JR, Miller GM, Goldman MS, Marsh WR: Spinal dural arteriovenous fistulas: $M R$ and myelographic findings. AJNR Am J Neuroradiol 16: 2049-2057, 1995

5) Hayashi K, Takahata H, Nakamura M: [Two cases of spinal arteriovenous malformation presenting with subarachnoid hemorrhage]. No Shinkei Geka 32: 605-611, 2004 (Jpn, with Eng abstract)

6) Hida K, Iwasaki Y, Goto K, Miyasaka K, Abe H: Results of the surgical treatment of perimedullary arteriovenous fistulas with special reference to embolization. J Neurosurg 90 (2 Suppl): 198-205, 1999

7) Holder CA: MR diffusion imaging of the cervical spine. Magn Reson Imaging Clin N Am 8: 675-686, 2000

8) Inci S, Akdemir P, Ozgen T: Spinal dural arteriovenous fistula and venous aneurysm: an unusual association. Surg Neurol 60: 334-338, 2003

9) Kataoka H, Miyamoto S, Nagata I, Ueba T, Hashimoto N: Venous congestion is a major cause of neurological deterioration in spinal arteriovenous malformations. Neurosurgery 48: 1224-1230, 2001

10) Le Bihan D, Breton E, Lallemand D, Grenier $P$, Cabanis E, Laval-Jeantet M: MR imaging of intravoxel incoherent motions: application to diffusion and perfusion in neurologic disorders. Radiology 161: 401-407, 1986

11) Mourier KL, Gobin YP, George B, Lot G, Merland JJ: Intradural perimedullary arteriovenous fistulae: results of surgical and endovascular treatment in a series of 35 cases. Neurosurgery 32: 885-891, 1993

12) Mullins ME, Grant PE, Wang B, Gonzalez RG, Schaefer PW: Parenchymal abnormalities associated with cerebral venous sinus thrombosis: assessment with diffusion-weighted MR imaging. AJNR Am J Neuroradiol 25: 1666-1675, 2004

13) Oldfield EH, Bennett A 3rd, Chen MY, Doppman JL: Successful management of spinal dural arteriovenous fistulas undetected by arteriography. Report of three cases. J Neurosurg 96 (2 Suppl): 220-229, 2002

14) Ries M, Jones RA, Dousset V, Moonen CT: Diffusion tensor MRI of the spinal cord. Magn Reson Med 44: 884-892, 2000

15) Schaefer PW, Grant PE, Gonzalez RG: Diffusionweighted MR imaging of the brain. Radiology 217: 331-345, 2000

16) Sibon I, Menegon P, Tafer N, Dousset V: Diffusion MRI in spinal dural arterio-venous fistula: a case report. Spinal Cord 44: 315-317, 2006

17) Spetzler RF, Detwiler PW, Riina HA, Porter RW: Modified classification of spinal cord vascular lesions. J Neurosurg 96 (2 Suppl): 145-156, 2002

Address reprint requests to: T. Takahashi, M.D., Department of Neurosurgery, Kohnan Hospital, 4-20-1 Nagamachi Minami, Taihaku-ku, Sendai 982-8523, Japan. 